TITLE:

High-purity hydrogen generation by ultraviolet illumination with the membrane composed of titanium dioxide nanotube array and Pd layer

$\operatorname{AUTHOR}(S):$

Hattori, Masashi; Noda, Kei; Matsushige, Kazumi

CITATION:

Hattori, Masashi ...[et al]. High-purity hydrogen generation by ultraviolet illumination with the membrane composed of titanium dioxide nanotube array and Pd layer. Applied Physics Letters 2011, 99(12): 123107.

ISSUE DATE:

2011-09

URL:

http://hdl.handle.net/2433/149204

RIGHT:

(C) 2011 American Institute of Physics 


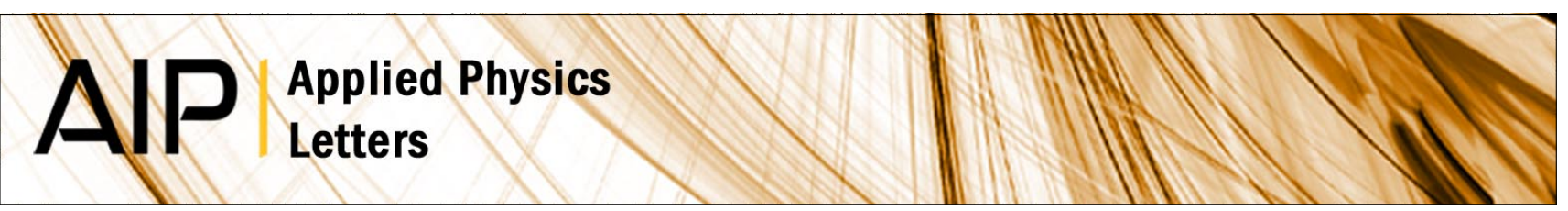

\section{High-purity hydrogen generation by ultraviolet illumination with the membrane composed of titanium dioxide nanotube array and Pd layer}

Masashi Hattori, Kei Noda, and Kazumi Matsushige

Citation: Appl. Phys. Lett. 99, 123107 (2011); doi: 10.1063/1.3643052

View online: http://dx.doi.org/10.1063/1.3643052

View Table of Contents: http://apl.aip.org/resource/1/APPLAB/v99/i12

Published by the American Institute of Physics.

\section{Related Articles}

Mott insulators: An early selection criterion for materials for photoelectrochemical $\mathrm{H} 2$ production

J. Renewable Sustainable Energy 3, 053101 (2011)

Promotion of hydrogen production using spectrally controlled thermal radiation

Appl. Phys. Lett. 97, 231908 (2010)

Carbon capture and storage: More energy or less carbon?

J. Renewable Sustainable Energy 2, 031006 (2010)

Hydrogen generation under visible light using nitrogen doped titania anodes

J. Appl. Phys. 107, 124305 (2010)

\section{Additional information on Appl. Phys. Lett.}

Journal Homepage: http://apl.aip.org/

Journal Information: http://apl.aip.org/about/about_the_journal

Top downloads: http://apl.aip.org/features/most_downloaded

Information for Authors: http://apl.aip.org/authors

\section{ADVERTISEMENT}

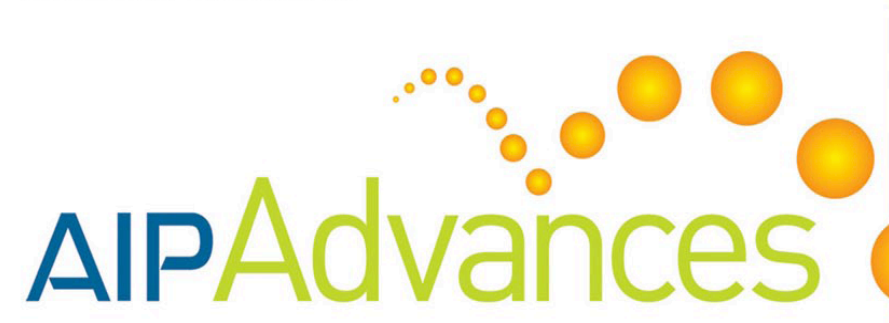

Submit Now

\section{Explore AIP's new \\ open-access journal}

Article-level metrics now available

Join the conversation!

Rate \& comment on articles 


\title{
High-purity hydrogen generation by ultraviolet illumination with the membrane composed of titanium dioxide nanotube array and Pd layer
}

\author{
Masashi Hattori, Kei Noda, ${ }^{\text {a) }}$ and Kazumi Matsushige \\ Department of Electronic Science and Engineering, Kyoto University, Katsura, Nishikyo, \\ Kyoto 615-8510, Japan
}

(Received 10 June 2011; accepted 1 September 2011; published online 20 September 2011)

\begin{abstract}
High-purity hydrogen generation was observed by using a membrane composed of a bilayer of an anodized titanium dioxide nanotube array (TNA) and a hydrogen permeable metal. This membrane was fabricated by transferring a TNA embedded in a titanium foil onto a sputtered 10- $\mu$ m-thick palladium film. Alcohols are reformed photocatalytically and concurrently generated hydrogen is purified through the $\mathrm{Pd}$ layer. $\mathrm{H}_{2}$ with a purity of more than $99 \%$ was obtained from liquid alcohols under ultraviolet illumination onto the membrane. Thus, we demonstrated the integration of photocatalytic hydrogen production and purification within a single membrane. (C) 2011 American Institute of Physics. [doi:10.1063/1.3643052]
\end{abstract}

Hydrogen gas $\left(\mathrm{H}_{2}\right)$ has been expected as one of the clean energy sources which can replace fossil fuels. $\mathrm{H}_{2}$ production has been performed with various methods, for example, steam reforming or partial oxidation of natural and synthesized gas, ${ }^{1-4}$ and electrolysis of water. ${ }^{5}$ In all these processes, the reforming units are followed by hydrogen purification units for separating generated $\mathrm{H}_{2}$ from other byproduct and residual gases. Moreover, reforming reactions usually need high temperatures of several hundred degrees Celsius. These constraints in $\mathrm{H}_{2}$ production limit miniaturization of efficient hydrogen production systems toward mobile applications such as on-site reformers.

For solving above-mentioned issues on hydrogen usage, in this communication, we propose a photoactive hydrogen production/separation membrane reactor which consists of an array of nanotubular photocatalyst and a hydrogen permeable metal as shown in Fig. 1. The whole thickness of this membrane reactor was only a few tens of micrometers. Anodized titanium dioxide $\left(\mathrm{TiO}_{2}\right)$ nanotube array (TNA) ${ }^{6-11}$ was employed as a photocatalyst and sputtered palladium thin film as a hydrogen purification part. ${ }^{12,13}$ Liquid and vapor fuels such as methanol and ethanol can be reformed by photocatalysis on TNA even at room temperature (Fig. 1(a)). The hollow parts of TNA serve as a path for generated $\mathrm{H}_{2}$ or protons to the inner surface of a palladium thin film (Fig. 1(b)), and then highly purified $\mathrm{H}_{2}$ gas was obtained quickly from the back side of the palladium thin film (Fig. 1(c)). The production of pure $\mathrm{H}_{2}$ clearly coincides with ON/OFF switching of ultraviolet (UV) illumination. This work demonstrates the integration of photocatalytic hydrogen production and purification within a single membrane, thereby suggesting that our photoactive membrane reactor is quite promising for achieving further miniaturization and lower temperature operation of various hydrogen reformers.

The photoactive hydrogen production/separation membrane was fabricated according to the process described hereinafter. A titanium foil (100 $\mu \mathrm{m}$ thick, $99.6 \%$ purity,

\footnotetext{
${ }^{\text {a) }}$ Author to whom correspondence should be addressed. Electronic mail: nodakei@kuee.kyoto-u.ac.jp, FAX: +81-75-383-2308.
}

Japan Metal Service) was degreased by sonication in acetone. TNA was formed by anodizing the Ti foil in a two electrode electrochemical cell with titanium as anode and platinum as cathode, with a constant voltage across the electrodes. Glycerol (99.0\% purity, Nakaraitesk) containing 0.5 wt. $\% \mathrm{NH}_{4} \mathrm{~F}$ (96.0\% purity, Wako Pure Chemical Industries) was used as electrolyte. Here, the circular area with a diameter of $1.7 \mathrm{~cm}$ in the middle of the foil was exposed to the electrolyte. After the anodization at $50 \mathrm{~V}$ for $20 \mathrm{~h}$, the foil was firstly annealed at $573 \mathrm{~K}$ in air for $30 \mathrm{~min}$ then annealed at $773 \mathrm{~K}$ in air for $3 \mathrm{~h}$, resulting in the TNA of anatase crystals confirmed by x-ray diffraction (not shown here). The surface morphologies of the TNA was observed using a Hitachi S4500 scanning electron microscope (SEM). SEM images of an anodized Ti foil, represented in Figs. 2(a) and 2(b), clearly show that the TNA with $5 \mu \mathrm{m}$ length and $40 \mathrm{~nm}$ pore size was formed under our experimental condition.

Successively, a 10- $\mu$ m-thick palladium layer was deposited on the surface of the TNA by RF magnetron sputter deposition. A pure palladium target (99.9\% purity, Furuya Metal Co.) was used as the sputtering source. During the Pd deposition, the sample temperature was kept at $673 \mathrm{~K}$ to promote the adhesion of Pd layer onto the TNA surface.

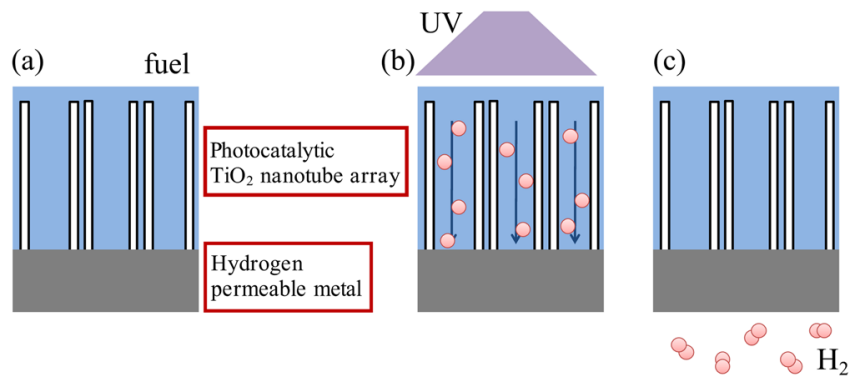

FIG. 1. (Color online) Functional mechanism of a photoactive hydrogen production/separation membrane based on a bilayer structure of an array of nanotubular photocatalyst and a hydrogen permeable metal. (a) A conceptual schematic of the hydrogen production/separation membrane. (b) Fuels (e.g., alcohols) are photo-oxidized on the surface of nanotubular photocatalyst and protons or $\mathrm{H}_{2}$ gas are formed. (c) Only $\mathrm{H}_{2}$ gas can be separated from other byproducts. 
(a)

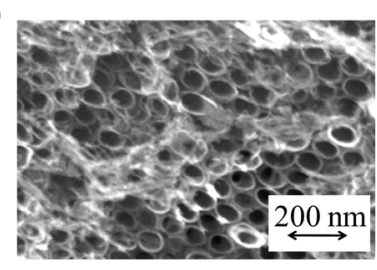

(b)

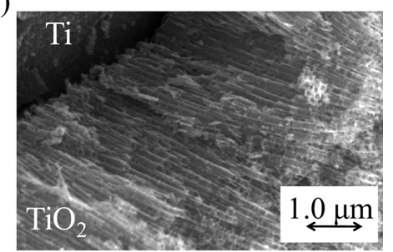

(c)

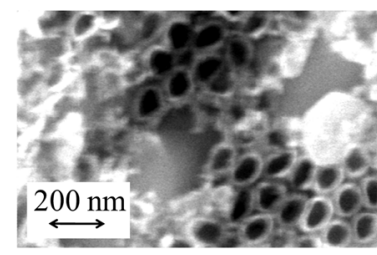

(d)

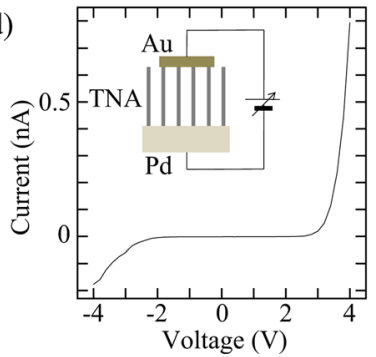

FIG. 2. (Color online) SEM images of the TNA in (a) top view and (b) cross-sectional view. (c) SEM image of the top surface of the TNA/Pd membrane. (d) A current-voltage $(I-V)$ curve of the Au/TNA/Pd sandwich structure prepared from the TNA/Pd membrane.

After the Pd deposition, the palladium layer was mechanically peeled off from the anodized Ti foil. This peel-off process made the TNA cracked at some defect sites on tubular surfaces and transferred onto the Pd surface. Figure 2(c) shows the image of the TNA transferred onto palladium layer, which clearly shows the $\mathrm{TiO}_{2}$ nanotubes with open apertures are standing on the palladium. Thus, a bilayer structure of the TNA and the Pd layer (TNA/Pd membrane) was prepared.

A current-voltage $(I-V)$ curve of the TNA/Pd bilayer structure was obtained with 2-point electrical measurement in air under dark condition using a Keithley 4200-SCS system. For this measurement, 50-nm-thick Au contacts with a diameter of $1 \mathrm{~mm}$ were formed on top of the TNA/Pd membrane by vacuum evaporation using a shadow mask. The obtained $I-V$ curve of the $\mathrm{Au} / \mathrm{TNA} / \mathrm{Pd}$ structure, shown in Fig. 2(d), displays a nonlinear curve which is typical of metal-semiconductor interfaces with Schottky barriers. The main charge carrier in $\mathrm{TiO}_{2}$ is electron because $\mathrm{TiO}_{2}$ is well known as an n-type oxide semiconductor. The work functions of $\mathrm{Au}(5.1 \mathrm{eV})$ and $\mathrm{Pd}(5.1 \mathrm{eV})$ are much larger than the conduction band level of $\mathrm{TiO}_{2}(4.0 \mathrm{eV})$. Therefore, the existence of Schottky barriers at both interfaces of Au/TNA and TNA/Pd is thought to be quite reasonable. The obtained $I$ - $V$ curve supports the formation of a rigid interface between the TNA and Pd in the TNA/Pd membrane.

Photoinduced hydrogen production and concurrent separation for the TNA/Pd membrane were examined with a home-made high vacuum cell as shown in Fig. 3. The cell was comprised by two chambers connected to a turbo-molecular pump and spatially separated by the membrane specimen. Hereafter, we call the upper chamber "chamber A" and the lower one "chamber B" for convenience. In order to mount the TNA/Pd membrane in the vacuum cell, the membrane was glued on a Ti sheet $(100 \mu \mathrm{m}$ thick, $3 \mathrm{~cm} \times 3 \mathrm{~cm})$ with a 1.5-cm-diameter aperture by using Torr seal epoxy resin.

After sufficient evacuation of both the chambers A and B to $1.0 \times 10^{-4} \mathrm{~Pa}$ with a turbo-molecular pump, the evacuation of the chamber A was stopped and alcohol vapors were introduced into the chamber A until the TNA surface of the

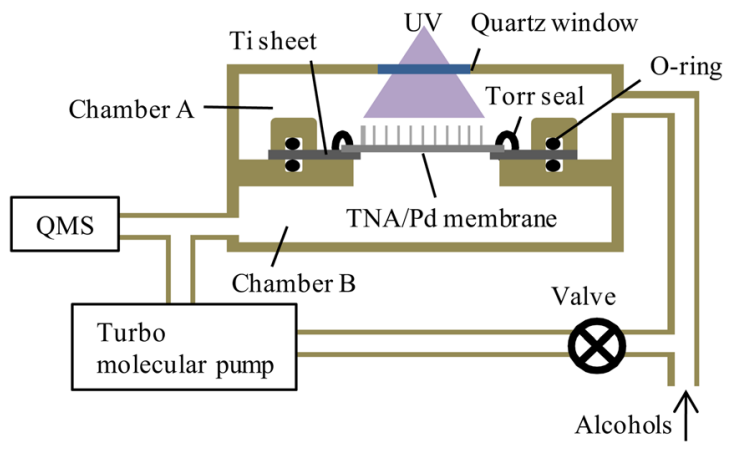

FIG. 3. (Color online) Schematic drawing of a high-vacuum characterization system for the TNA/Pd membrane reactor. The performance of $\mathrm{H}_{2}$ production and separation was evaluated using a QMS and a home-made vacuum cell.

membrane became submerged in an alcohol droplet. Even after the introduction of alcohols into the chamber $\mathrm{A}$, the degree of vacuum in the chamber $\mathrm{B}$ was maintained to be $1.0 \times 10^{-4} \mathrm{~Pa}$, suggesting the supreme mechanical robustness of the TNA/Pd membrane. Successively, photocatalytically generated hydrogen and other byproduct gases filtered through the TNA/Pd membrane were detected at a real-time scale by a six-channel quadrupole mass spectrometer (QMS, Vacscan/Spectra) installed for detecting residual gases inside the chamber B. Measurements of the gas spectra were performed with the repetitive ON/OFF of illumination from a Xe lamp (LAX-101, Asahi Spectra). The incident light was filtered with a band-pass filter between 300 and $400 \mathrm{~nm}$, and the intensity was set to be $30 \mathrm{~mW} / \mathrm{cm}^{2}$ on the TNA. All the measurements were performed at room temperature.

In photocatalytic $\mathrm{H}_{2}$ production from methanol on $\mathrm{TiO}_{2}$ surface, methanol undergoes oxidative decomposition to $\mathrm{CO}_{2}$ through intermediates, e.g., formaldehyde $\left(\mathrm{CH}_{2} \mathrm{O}\right){ }^{14,15}$ Figure 4(a) shows a simultaneous analysis of various gases generated from methanol photocatalytic decomposition with the TNA/Pd membrane; $\mathrm{H}_{2}(\mathrm{~m} / \mathrm{e}=2), \mathrm{CO}_{2}(\mathrm{~m} / \mathrm{e}=44)$, and $\mathrm{CH}_{2} \mathrm{O}(\mathrm{m} / \mathrm{e}=30)$. These partial pressures were measured from residual gases in the chamber $\mathrm{B}$. The $\mathrm{H}_{2}$ pressure revealed a switching phenomenon according to the $\mathrm{ON}-\mathrm{OFF}$ interval of UV illumination (30 $\mathrm{min} / 20 \mathrm{~min})$ and the net increase in the $\mathrm{H}_{2}$ pressure under UV illumination was about $1.0 \times 10^{-5} \mathrm{~Pa}$. On the other hand, the $\mathrm{CO}_{2}$ and $\mathrm{CH}_{2} \mathrm{O}$ pressures did not show any switching phenomena regardless of UV illumination. This means that $\mathrm{CH}_{2} \mathrm{O}$ and $\mathrm{CO}_{2}$ detected in
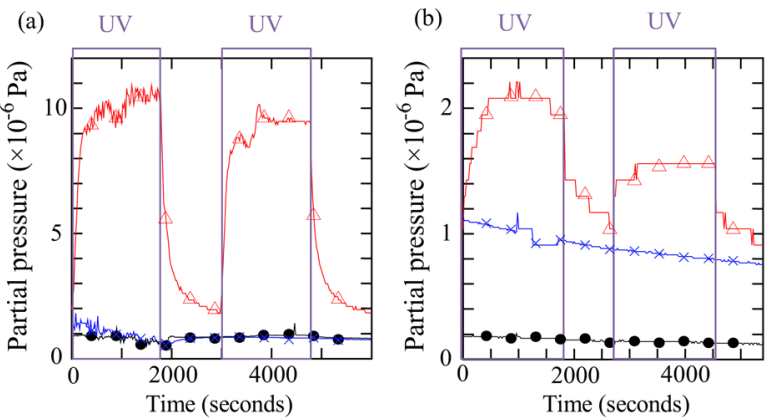

FIG. 4. (Color online) Temporal variation of partial pressures of gas species generated from (a) methanol and (b) ethanol photocatalytic decomposition with the TNA/Pd membrane: $\mathrm{H}_{2}(\mathrm{~m} / \mathrm{e}=2$, open triangle $), \mathrm{CO}_{2}(\mathrm{~m} / \mathrm{e}=44$, cross), and formaldehyde $\left(\mathrm{CH}_{2} \mathrm{O}\right)(\mathrm{m} / \mathrm{e}=30$, solid circle). These partial pressures were monitored from residual gases in the chamber $\mathrm{B}$. 
Fig. 4(a) were not byproducts due to the function of the TNA/Pd membrane but originally existed inside the chamber $\mathrm{B}$ as background gases.

Here, the purity of $\mathrm{H}_{2}(x)$ produced with the TNA/Pd membrane is defined as follows:

$$
x=\frac{\Delta P_{\mathrm{H} 2}}{\Delta P_{\mathrm{H} 2}+\Delta P_{\mathrm{CH} 2 \mathrm{O}}+\Delta P_{\mathrm{CO} 2}},
$$

where $\Delta P_{\mathrm{H} 2}, \Delta P_{\mathrm{CH} 2 \mathrm{O}}$, and $\Delta P_{\mathrm{CO} 2}$ stand for the net increase of partial pressure for each gas species with UV illumination. The increase of partial pressure is obtained by subtracting the background pressure from the average pressure under UV illumination. From the data in Fig. 4(a), the purity of generated $\mathrm{H}_{2}$ was estimated to be $100 \%$ at the first UV illumination and $99 \%$ at the second UV illumination. These results reveal that the TNA/Pd membrane reactor produced high-purity $\mathrm{H}_{2}$ from methanol rapidly with UV illumination.

The simultaneous $\mathrm{H}_{2}$ production and separation were also confirmed in the case of ethanol decomposition as shown in Fig. 4(b). Only the $\mathrm{H}_{2}$ pressure displayed a switching phenomenon with the ON/OFF (30 min/15 min) of UV irradiation. Pressures of $\mathrm{CO}_{2}$ and $\mathrm{CH}_{2} \mathrm{O}$ were not changed with the UV irradiation, although the background levels of these gas species were gradually shifted. The net increase in $\mathrm{H}_{2}$ pressure under UV illumination was about $1.0 \times 10^{-6} \mathrm{~Pa}$, and the purity of produced $\mathrm{H}_{2}$ calculated from Eq. (1) was $100 \%$ at both first and second UV illumination. Accordingly, high-purity $\mathrm{H}_{2}$ can be also produced from ethanol by using the TNA/Pd membrane reactor.

In the TNA/Pd membrane, two possible processes for high-purity $\mathrm{H}_{2}$ production are considered. $\mathrm{H}_{2}$ gas can be formed on the TNA side with the aid of Pd, which can work as cocatalyst for proton reduction, and then penetrate into the Pd layer in the form of proton. However, it is also possible that photocatalytically generated protons on the TNA side can reach the surface of the Pd layer directly without proton reduction. The investigation of the functional mechanism of the TNA/Pd membrane is going on and of great importance for realizing more efficient high-purity hydrogen production.

In conclusion, we developed the photoactive hydrogen production/separation membrane based on a bilayer structure of a TNA with open apertures and a metallic hydrogen permeation film. Integration of nanostructured photocatalyst and hydrogen permeation materials, exemplified in this study, is one of the promising strategies for realizing more efficient, and compact hydrogen reforming systems with the aid of solar energy.

This work was partly supported by Global Center of Excellence (G-COE) program of the Ministry of Education, Culture, Sports, Science and Technology of Japan.

\footnotetext{
${ }^{1}$ M. Oertel, J. Schmitz, W. Werich, D. J. Neumann, and R. Schulten, Chem. Eng. Technol. 10, 248 (1987).

${ }^{2}$ D. K. Liguras, D. I. Kondaraides, and X. E. Verykios, Appl. Catal. B 43, 345 (2003).

${ }^{3}$ T. J. Huang and S. W. Wang, Appl. Catal. 24, 287 (1986).

${ }^{4}$ L. Alejo, R. Lago, M. A. Pena, and J. L. G. Fierro, Appl. Catal. A 162, 281 (1997).

${ }^{5}$ W. Doenitz, R. Schmidberger, E. Steinheil, and R. Streicher, Int. J. Hydrogen Energy 5, 55 (1980).

${ }^{6}$ J. M. Macak, H. Tsuchiya, L. Taveira, S. Aldabergerova, and P. Schmuki, Angew. Chem. Int. Ed. 44, 7463 (2005).

${ }^{7}$ J. H. Park, O. O. Park, and S. Kim, Appl. Phys. Lett. 89, 163106 (2006).

${ }^{8}$ Y. Hou, X. Y. Li, Q. D. Zhao, X. Quan, and G. H. Chen, Appl. Phys. Lett. 95, 093108 (2009).

${ }^{9}$ X. F. Gao, W. T. Sun, G. Ai, and L. M. Peng, Appl. Phys. Lett. 96, 153104 (2010).

${ }^{10}$ O. K. Varghese, M. Paulose, and C. A. Grimes, Nature Nanotechnol. 226, 592 (2009).

${ }^{11}$ M. Hattori, K. Noda, K. Kobayashi, and K. Matsushige, Phys. Status Solidi C 8, 549 (2011).

${ }^{12}$ V. Jayaraman, Y. S. Lin, M. Pakala, and R. Y. Lin, J. Membr. Sci. 99, 89 (1995).

${ }^{13}$ L. S. Mcleod, F. L. Degertekin, and A. G. Fedorov, Appl. Phys. Lett. 90, 261905 (2007).

${ }^{14}$ T. Kawai and T. Sakata, J. Chem. Soc., Chem. Commun. 1980, 694 (1980).

${ }^{15}$ T. L. Villarreal, R. Gomez, M. Neumann-Spallert, N. Alonso-Vante, and P. Salvador, J. Phys. Chem. B 108, 15172 (2004).
} 